\title{
Gross Anatomical Studies on the Celiac Artery in Cattle Egret (Bubulcus ibis) with Special Reference to the Arterial Supply of the Stomach
}

E. F. Khalifa

Anatomy Department, Faculty of Veterinary Medicine, Cairo University, EGYPT

\section{Abstract}

The present study was carried out on ten adult, apparently healthy cattle egrets of different ages and sexes. Each bird was exsanguinated and the descending aorta was cannulated and flushed with warm normal saline solution $(0.9 \%)$, then injected with red colored gum milk latex. The origin, course and distribution of the celiac artery were described. The celiac artery erupted from the right face of the descending aorta opposite to the $4^{\text {th }}$ or $5^{\text {th }}$ vertebral rib, on a level with the junction of the esophagus and the proventriculus. It gave off the Aa. esophageales, A. proventricularis dorsalis, Aa. lienales, and A. hepati$\mathrm{ca}$, then bifurcated into left and right branches. The left branch of the celiac artery gave off $A$. proventricularis ventralis and A.gastrica ventralis then continued as the A.gastrica sinistra. The right branch of the celiac artery released the Aa. lleoce- cales, Rr. succi, A. gastroduodenalis, A. gastrica dextra then continued as $A$. pancreaticoduodenalis.

Keywords: Ventriculus- Proventriculus- Celiac artery- Cattle egret.

\section{Introduction}

Cattle egret belongs to Family Ardeidae, feeds on a wide range of prey, particularly insects and moths as well as spiders, frogs, earthworms and fishes and is locally distributed in Nile Delta and Valley.

The importance of cattle egret to the farmer has initiated an increasing interest to establish more accurate and specific anatomical facts about the arterial blood supply of the gastrointestinal tract of cattle egret.

The present study is therefore an attempt to provide some additional information on the celiac artery of cattle egret; which had received but little attention in field of veterinary anatomy. 


\section{Material and Methods}

The current study was conducted on ten adult, apparently healthy cattle egrets of both sexes which obtained from the farmer farms. Before exsanguinations, egrets were anaesthetized by IM injection of $0.5 \mathrm{cc}$ of $2 \%$ xylazine $\mathrm{HCL}(3 \mathrm{mg} / \mathrm{kg})$, followed by the injection of heparin (Cal Heparin, 5000 I.U.) in the wing vein to prevent blood clotting.

Each bird was then exsanguinated through the common carotid arteries and left to bleed for five minutes, the breast muscle and sternum were carefully removed to expose the heart. The descending aorta was cannulated and flushed with normal saline. The birds were injected with $60 \%$ gum milk latex colored red with Rotring ${ }^{\circledR}$ ink. (Tompsett and WakeIly, 1965).

The birds were left in a mixture of $10 \%$ formalin, $2 \%$ phenol and $1 \%$ glycerin for three days before the routine dissection. The obtained results were photographed using Sony® digital camera $12.1 \mathrm{mp}, 4 \mathrm{x}$. The nomenclature used was that recommended by the Nomina Anatomica Avium (Baumel et. al., 1993).

\section{Results}

\section{A. Celiaca:}

The celiac artery (Figs 1,2/2) is the first visceral branch of the descending aorta (Figs 1, 2/1). It originated from the right side of the descending aorta opposite to the $4^{\text {th }}$ or $5^{\text {th }}$ vertebral rib, on a level with the junction of the esophagus and the proventriculus. The celiac artery extended ventrally for about $2-3 \mathrm{~cm}$, then gave off the esophageal arteries, dorsal proventricular artery and continued caudoventrally to give about 4-5 splenic arteries and hepatic artery. Finally it terminated beyond the caudal end of the spleen by $1-2 \mathrm{~cm}$ into left and right branches of the celiac. It supplied the esophagus, proventriculus, ventriculus, spleen, liver, duodenum, pancreas, parts of ileum and the cecum.

\section{Aa. Esophageales:}

The esophageal arteries (Figs 1, 2, $3 / 4$ ) were represented by two arteries; the first was derived from the celiac artery after 3-5 $\mathrm{mm}$ from its origin, the other branch derived from the celiac artery after $6-8 \mathrm{~mm}$ from its origin just above the origin of the dorsal proventricular artery. The esophageal arteries proceeded cranially on the dorsal aspect of the thoracic esophagus, giving off fine twigs (Figs 1, 3/4a) to that portion and finally anastomosed with the esophageal branch of the esophagotracheobronchial artery.

\section{A. Proventricularis dorsalis:}

The dorsal proventricular artery (Figs 1, 2, 3/5) arose from the left aspect of celiac artery, $0.5 \mathrm{~cm}$ cau-

Vol 7 No 1, (2014) 1 - 13 
dal to the emergence of the esophageal artery. It gave off 1-2 esophageal branches (Figs 1, 2, 3/6) that proceeded cranially to the esophagus, and then extended caudally along the dorsal aspect of the proventriculus to be terminated in the isthmus of the stomach. During its course on the proventriculus, it detached 2-3 esophageal branches (Figs 1, 2/5a) which ramified in the junction of the esophagus with proventriculus and $2-3$ collateral branches (Figs 1, 2/5b) to the dorsal wall of the proventriculus and Isthmus gastris.

\section{Aa. Splenicae (Aa. Lienales):}

The splenic arteries (Fig 1/7) were represented by 5-6 branches, sprang from the celiac artery about $1 \mathrm{~mm}$ from the origin of the dorsal proventricular artery. The three cranial branches passed to the cranial pole of the spleen, while the caudal 2-3 branches were distributed in the caudal pole of the spleen.

\section{A. hepatica:}

The hepatic artery (Figs 1, 2/ 8) originated from the celiac artery at the level of the caudal pole of the spleen; entered the porta hepatis then divided into right and left hepatic arteries to supply the two lobes of the liver and gall bladder. It also supplied the duodenojejunal flexure.

\section{Ramus sinister arteriae celiacae:}

The left branch of celiac artery (Figs $1,2,3 / 10)$ is one of the two divergences of the celiac artery just after the detachment of the splenic arteries. It passed to the left side between the proventriculus and isthmus to provide the $A$. proventricularis ventralis and A.gastrica ventralis, and then continued as the A.gastrica sinistra. During its course it detached 3-4 small branches to the isthmus and the cranio-dorsal sac of the ventriculus.

\section{A. Proventrcularis ventralis:}

The ventral proventricular artery (Fig 3/11) detached from the left branch of the celiac artery at the distal third of the proventriculus. It took a short dorsal course to supply the wall of the proventriculus with 12 branches and then terminated into 2-3 fine twigs that supplied the terminal part of the ventral aspect of the thoracic esophagus (Fig 3/11 a).

\section{A. gastrica ventralis:}

The ventral gastric artery (Figs 2 and $3 / 12$ ) emanated from the ventral aspect of the left branch of the celiac artery at the level of the isthmus. It gave off collateral branches to the ventral aspect of the proventriculus and isthmus. It proceeded caudally along the ventral margin of the ventriculus giving off collateral rami to that portion. Here, it anas- 
tomosed with those branches of right gastric arteries in the vicinity of the caudal sulcus of the ventriculus.

\section{A. gastrica sinistra:}

The left gastric artery (Fig 3/13) was the direct continuation of the left branch of the celiac artery beyond the detachment of the ventral proventricular and ventral gastric arteries. It passed in the groove between the Pars pylorica (third stomach) and Ventriculus. The left gastric artery had a fan-like distribution as it terminated into 6-8 rami in the left ventral aspect of the Ventriculus to supply the craniodorsal tenuis, caudoventral tenuis muscles. Along its course it gave of 2-3 collateral branches (Fig 3/14) to supply the distal third of the Proventriculus and a single branch to the Pars pylorica (Fig 3/15).

\section{Ramus dexter arteriae celicae:}

The right branch of the celiac artery (Figs 1, 2/9) was the larger of the two terminal branches of the celiac artery. From its size and direction it is considered as the direct continuation of the parent vessel. It proceeded in a caudoventral direction reaching the right aspect of the pylorus. Along its course the right branch of the celiac artery gave off; Aa. ileocecales, Rr. succi, A. gastroduodenalis, Aa. jejunales, A. gastrica dextra, then after continued as A. pancreaticoduodenalis.

J. Vet. Anat.

\section{Aa. ileocecales:}

The ileocecal arteries (Figs 1, 2/ 16) were 1-2 branches, detached from the right branch of the celiac artery after its origin by $1 \mathrm{~mm}$, These branches entered the short ileocecal ligament and distributed in the caudal third of the ileum and the body of the left cecum by short cecal branches (Fig 2/ 16 a).

\section{Rr. succi:}

The branches of the Pars pylorica (third stomach) (Figs 1, 2/17) were represented by 1-2 branches which were released from the right branch of the celiac artery just above the origin of gastroduodenal artery.

\section{A. gastroduodenalis:}

The gastroduodenal artery (Figs 1, $2 / 18$ ) was a short vessel, originated from the left wall of the right branch of the celiac artery. It was ramified in the pyloric region and the initial portion of the duodenum descendens.

\section{Aa. jejunales:}

The jejunal arteries were represented by two arteries, the former (Figs $1,2 / 19$ ) originated from the right branch of the celiac artery at the same level of origin of gastroduodenal artery. It proceeded caudodorsally to supply the terminal part of jejunum, jejunoileal flexure and initial part of ileum. The second artery (Figs 1, 2/20) was detached from 
the proximal third of the pancreaticoduodenal artery. It proceeded dorsally for a short distance, then divided into two branches, one of them (Fig 2/20 a) supplied the initial portion of the jejunum and ended by anastomosis with the similar branch of the cranial mesenteric artery (Figs $1,2 / 3$ ) on this level. Another branch (Fig $2 / 20$ b) supplied the terminal part of the jejunum.

\section{A. gastrica dexter:}

The right gastric artery (Figs 1, 2/21) was represented by a vessel of about $2-3 \mathrm{~cm}$ long that originated from the right branch of the celiac artery at the level of the ascending part of duodenum. It proceeded for about 2-3 $\mathrm{mm}$ on the right dorsal aspect of the ventriculus and had a fan-like distribution as it is arborized into 8-10 rami to supply the craniodorsal tenuis, caudoventral tenuis muscles and centrum tendineum. The last 2-3 branches anastomosed with the corresponding branch of the left gastric artery.

\section{A. pancreaticodudenalis:}

The pancreaticoduodenal artery (Figs $1,2 / 22$ ) was considered as the direct continuation of the right branch of the celiac artery next to the origin of the right gastric artery. It passed along the mesodudenum between the descending and ascending limbs of the duodenum where it released a series of branches to the pancreas and duo- denal loop. Along its course, it gave off Rr. pancreatici (Figs 1, 2/23) and Rr. duodenales (Figs 1, 2/24). These rami were detached at different levels and ramified in the corresponding organs. It also gave of the second jejunal artery (Fig 1, 2/20).

\section{Discussion}

The present study revealed that, the celiac artery in cattle egret is the first visceral branch of the descending aorta, supplied the proventriculus, ventriculus, liver, spleen, pancreas, duodenum, parts of ileum and the left ceca. This was in agreement with (Kuru, 2010; Kurtul and Haziroglu, 2002; Aslan and Takci, 1998; Silva et al., 1997; Fowler, 1991; King and Mc Lelland, 1984; Lauper et al., 1975) in domestic fowl.

The celiac artery was detached from the right face of the descending aorta opposite to the $4^{\text {th }}$ or $5^{\text {th }}$ vertebral rib, on a level with the junction of the esophagus and the proventriculus. While, Haligur and Duzler (2010) reported that, the celiac artery arose at the level of the 2-3 ribs. On the other hand, (Kuru, 2010; Kurtul and Haziroglu, 2002; Dursun, 2002; Franz and Salomon, 1993; Miladinovic et al., 1986; King and Mc Lelland, 1984; Lauper et al., 1975) mentioned its origin from the descending aorta at the $5^{\text {th }}-6^{\text {th }}$ thoracic vertebra ventrally. 
The celiac artery gave off the esophageal arteries, dorsal proventricular artery then extended caudoventrally giving off 5-6 splenic branches and hepatic artery, finally it divided into left and right branches. Silva et al. (1997) added that the celiac artery of fowl sent a vessel to the pericardium called the cardiac artery. Aycan and Duzler (2000) reported that the celiac artery in the eagle owl did not bifurcate and gave off nine branches.

In accordance to (Kuru, 2010; Aycan and Duzler, 2000; Malinovsky, and Visnansk 1975; Mc Leod et al., 1964) in the domestic goose and Nickel et al., (1977) in fowl, the first branch from the celiac artery is the esophageal artery. On the other hand, the first branch of the celiac artery is the dorsal proventricular artery, that reported by Kurtul and Haziroglu, (2002); and Silva et al., (1997) in rooster, drake, pigeons and geese and Haligur and Duzler (2010) in the red falcon. Baumel et al., (1993) in the family Falconidae described the esophageal artery as stemming from the aorta. In the present study, the esophageal artery was not observed to arise from the aorta.

The present investigation reported that, the dorsal proventricular artery was detached from the celiac artery after $0.5 \mathrm{~cm}$ from the origin of the esophageal artery. In the contrast, Kuru (2010) stated this distance as 4 $\mathrm{mm}$. While, Haligur and Duzler,
(2010) in the red falcon mentioned that this branch was originated in common with the esophageal artery. Nishida et al. (1969) named this vessel as the right glandular gastric artery. The dorsal proventricular artery in egret does not change its name, on the other hand this artery continue as dorsal gastric artery that reported by Kuru, (2010); Haligur and Duzler, (2010); Aycan and Duzler (2000); and Aslan and Takci (1998); while Silva et al., 1997 described the dorsal gastric artery as a continuity of the pancreaticoduodenal artery in birds.

The left branch of the celiac artery in cattle egret provided the ventral proventricular artery, ventral gastric artery and continued as the left gastric artery, that in agreement with Kuru (2010); Haligur and Duzler, (2010); Getty, (1975). Moreover, Haligur and Duzler, (2010) reported that, the left branch of the celiac artery started at the right and gave off the right hepatic artery before coursing to the left.

In the present study as well as in the domestic fowl by Kuru, (2010), the ventral gastric artery was originated from the left branch of the celiac artery, and extended caudally along the ventral aspect of the ventriculus. Haligur and Duzler (2010) in red falcon recorded that the ventral gastric artery was represented by 2-3 vessels. Nickel et al. (1977) in the fowl mentioned that the ventral gastric artery was continued as the A. gastro- 
pancreaticoduodenalis from which arose a branch going to the muscular stomach and rami ileocaecales to the middle section of the ceca and the ileum then it continued as the A. pancreaticoduodenalis.

The present study revealed that the left gastric artery was represented the direct continuation of the left branch of the celiac artery. It had a fan-like distribution as it was terminated into 6-8 rami in the left ventral aspect of the ventriculus, simulating that recorded by Haligur and Duzler (2010) in red falcon. Kuru (2010) in the domestic fowl revealed that the left gastric artery divided into two branches, the dorsal left and ventral left gastric arteries. Mahdy (2009) in the ostrich added that the left gastric artery gave off 5-7 dorsal twigs and 4-6 ventral collateral twigs before its bifurcation into dorsal and ventral terminal branches.

In this study the hepatic artery originated from the celiac artery before its bifurcation, as reported by, Aycan and Duzler, (2000) in Eurasian eagle owl. While Kuru, (2010); Dursun, (2002); Kurtul, (2002); and Malinovsky and Visnanska, (1975) mentioned that the left hepatic artery was a branch of the ventral gastric artery in the domestic fowl. In contrast, (Baumel et al., 1993) in ducks, (Nickel et al., 1977) in chickens, (Malinovsky and Novotna, 1977) in red falcons and (Haligur and Duzler, 2010) stated that, the left he- patic artery arose from the left branch of the celiac artery. On the other hand, (Kuru, 2010; Dursun, 2002; Kurtul, 2002; Aslan and Takci, 1998; Baumel et al., 1993; Nickel et al., 1981; Malinovsky and Novotna, 1977; Malinovsky and Visnanska, 1975; Malinovsky et al., 1973; Malinovsky, 1965; Mc Leod et al., 1964;) recorded that, the right hepatic artery was detached from the right branch of the celiac artery.

In cattle egret the splenic arteries were represented by 5-6 branches, while they were two branches as recorded in the chicken by Kuru, (2010) and Kuru (1996) and in the Eurasian eagle owl by Aycan and Duzler (2000). The number of splenic arteries in chickens has been reported to be 2-8 in domestic fowl by Malinovsky and Novotna (1977), 2-6 in the duck by Pinto et al. (1998), 3-6 in the pigeon and 4-6 in the rooster by Kurtul (2002). The origin of the splenic arteries directly from the celiac artery which was also recorded by Haligur and Duzler (2010) in red falcon, Aycan and Duzler (2000) in the Eurasian eagle owl and Chiasson (1964), Baumel et al. (1993) in the chicken. While, (Kuru, 2010; Dursun, 2002; Aslan and Takci, 1998; Baumel et al., 1993; Malinovsky et al., 1973; Doguer and Erencin, 1964) in the fowl, recorded that the origin of the splenic arteries from is the right branch of the celiac artery. 
In cattle egret the right branch of the celiac artery gave off the ileocecal, gastroduodenal, right gastric arteries and then continued as pancreaticoduodenal artery. (Kuru, 2010; Aslan and Takci, 1998; Silva et al, 1997; Franz and Salomon, 1993; Baumel, 1975) added that, the splenic arteries, right hepatic artery, ileal arteries also originated from the right branch of the celiac artery. In the study, the right branch of the celiac artery gave off the jejunal artery and branch to Pars pylorica.

In the present investigation, the ileocecal artery arose from the right branch of the celiac artery. While it is originated from the pancreaticodudenal artery as reported by, Kuru, (2010) and Silva et al. (1997) in domestic fowl and Haligur and Duzler, (2010) in the red falcon. On the other hand, the ileocecal artery arose from the cranial mesenteric artery as recorded by, (Kurtul and Haziroglu, 2002) in the pigeon. In this connection, in the fowl, Baumel (1975), Malinovsky and Novotna (1977) and Nickel et al. (1977) recorded 1-5 ileocecal arteries were arising from the duodenojejunal artery. The ileocecal artery supplied the ileum in the pigeon (Kurtul and Haziroglu, 2002; and Silva et al., 1997) and Haligur and Duzler (2010) in the red falcon. While, in the present study and results of $\mathrm{Ku}$ $r u$, (2010) in domestic fowl, the ile-

J. Vet. Anat. ocecal artery supplied the left cecum and the terminal part of the ileum

In cattle egret, the gastroduodenal artery originated from the right branch of the celiac artery. It was distributed to craniodorsal tenuis muscle, the pylorus and the initial portion of the duodenum descendens. Similar results were recorded by (Kuru, 2010) in the domestic fowl and (Haligur and Duzler, 2010) in red falcon. On the other hand Baumel et al. (1993) reported the corresponding vessel in the chicken as arising from the left branch of the celiac artery.

The current investigation revealed that the pancreaticoduodenal artery represented the continuation of the right branch of the celiac artery, as recorded by (Kuru, 2010), in fowl. While Mahdy (2009) in the ostrich revealed the bifurcation of the right branch of the celiac artery into the right gastric and pancreaticoduodenal arteries. On the other hand Nickel et al. (1977) recorded that the pancreaticoduodenal artery was formed by the continuity of the gastropancreaticoduodenal artery. In cattle egret as in the fowl by (Kuru, 2010) the pancreaticoduodenal arteries run in the mesentery connecting the ascending and descending parts of the duodenum to the flexura duodeni, giving off Rr. pancreatici and $\mathrm{Rr}$. duodenales, in the study it 
also gave jejunal artery. In this respect in the red falcon (Haligur and Duzler, 2010), recorded that this artery was divided into two branches, one of the bifurcated branches extended along the flexura duodeni and pars descendens duodeni while the other branch was ascertained to run along the pars ascendens duodeni.

\section{References}

Aslan, K. and Takci, I. (1998): The arterial vascularisation of the organs (stomach, intestine, spleen, kidneys, testes and ovarium) in the abdominal region of the geese obtained from Kars surrounding (in Turkish). Kafkas University, Fac. Vet. Med. J., 4: 49-53.

Aycan, K. and Duzler, A. (2000): The anatomy of celiac artery in the eagle owl (Bubo bubo) (in Turkish). Ankara University, Fac. Vet. Med. J., 47: 319-323.

Baumel, J. J. (1975): Aves Heart and Blood Vessels. In, Sisson and Grossman's the Anatomy of the Domestic Animals. Getty R (Eds.), Vol II, 5 th ed. Saunders Company, Philadelphia, 1990-1991.

Baumel, J. J., King, S. A., Breasile , J. E., Evans, H. E. and Berge, J. C. V. (1993) : Nomina Anatomica Avium. Published by the Nuttall Or- nithological Club. No:23,Cambridge, Massachusets.

Chiasson, B. R. (1964): Laboratory of the Pigeon. Brown Company Publishers, Dubuque, lowa, pp. 3441.

Doguer, S., Erencin, Z. (1964): Comparative Anatomy of Domestic Bird. The Veterinary Medicine Faculty Publishers, Ankara University Press, Ankara, pp. 72-73.

Dursun, N. (2002): Anatomy of Domestic Birds (in Turkish). Medisan Publishing, Ankara, pp. 140-141.

Fowler, M. E. (1991): Comparative clinical anatomy of ratites. J. Zool. Wild. Med., 22: 204-227.

Franz, V. and Salomon, V. (1993): Lehrbuch der Geflügelanatomie. Gustav Fischer Verlag, Jena, Suttgart.

Getty R. (1975): The Anatomy of the Domestic Animals. 5th ed. WB Saunders Company, New York. 1990-1991.

Haligur, A. and Duzler, A. (2010): Course and branch of the celiac artery in the red falcon (Buteo rufinus). Vet. Med., 55(2): 79-86.

King, A. S. and Mc Lelland, J. (1984): Birds, Their Structure and Function. $2^{\text {nd }}$ ed., Bailliere Tindall, England. 
Kurtul, I. (2002): Comparative macroanatomical investigations on the pattern and branches of the aorta descendens among the rooster, drake, and pigeon (in Turkish). [PhD thesis.] Fac. Vet. Med. Ankara Univ., pp. 24-37.

Kurtul, I. and Haziroglu, R. M. (2002): Comparative macroanatomical investigations on the pattern and branches of the descending aorta among the rooster, drake, and pigeon (in Turkish). J. Fac. Vet. Med., Ankara Univ., 51: 1-6.

Kuru, N. (1996): Macroanatomical investigation of course and branching of aorta in domestic chick and New Zealand rabbit (in Turkish). [PhD thesis] Faculty of Biology, Selcuk University.30-37.

Kuru, N. (2010): Macroanatomic investigations on the course and distribution of the celiac artery in domestic fowl (Gallus gallus domesticus). Scientific Research and Essays Vol.5 (23), pp. 3585-3591.

Lauper, N. T., Unni, K. K., Kottke, B. A. and Titus, K. L. (1975): Anatomy and histology of aorta of White Carneau pigeon. Lab. Invest., 32: 536-551.

Mahdy, E.A.A. (2009): some anatomical studies on the stomach of ostrich (Struthio camelus).M.V.Sc. Thesis, Fac. Vet. Med. Zagazig Univ.
Malinovsky, L. (1965): Blood supply to stomachs and adjacent organs in Buzzard. Folia Morphologica (Praque), 13: 191-201.

Malinovsky, L. and Novotna, M. (1977): Branching of the celiac artery in some domestic birds. III. A. Comparison of the pattern of the celiac artery in three breeds of the domestic fowl (Gallus gallus f. domestica). Anat. Anz, 141: 136-146.

Malinovsky, L. and Visnanska, M. (1975): Branching of the celiac artery in some domestic birds, II. The domestic goose. Folia Morphologica (Prague). 23: 128-135.

Malinovsky, L., Visnanska, M. and Roubal, P. (1973): Branching of a. celiaca in some domestic birds. I. Domestic Duck (in Czech). Scripta Medica, 46: 325-336.

McLeod, W. M., Trotter, D. M. and Lumb, J. M. (1964): Avian Anatomy. Burgeaa Publishing Company, 82: 133-134.

Miladinovic, Z., Popoic, S. and Jojic, D. (1986): Vascularization of the glandular stomach of the hen (Gallus domesticus). Acta Vet., 5(6): 335-342.

Nickel, R., Schummer, A. and Seiferle, E. (1977): Anatomy of the Domestic Birds. Verlag Paul Parey, Berlin. 
Nickel, R., Schummer, A. and Seiferle, E. (1981): The Anatomy of the Domestic Animals. Vol 3, Verlag Paul Parey, Berlin, 95.

Nishida, T., Paik, Y. K. and Yasuda, M. (1969): Blood vascular supply of the glandular stomach (Ventriculus glandularis) and the muscular stomach (Ventriculus muscularis). Jpn. J. Vet. Sci., 31: 51-70.

Pinto, M. R. A., Riberio, A. A.CM. and Souza, W. M. (1998): Os arranjos configurados pela arteria celiaca no pato domestico (Carina moshata). Braz. J. Vet. Res. Anim. Sci., 35: 103-106.

Silva, Carneiro, F. O., Severino, R. S., Santos ALQ, Drummond, S. S., Bombonato, P. P., Santana, MIS., Lopes, D. and Marçal, A. V. (1997): Origin and distribution of the artery celiacae in birds (Gallus gallus domesticus-Ross linage). Revista da FZVA,4 (1): 64-76.

Tomsett, D. H. and C. W. Wakeley (1965): Anatomical Techniques. 1st Edition. E \& Living Stone Ltd. Edinburgh and London.

Table (1): Summary for the main arteries supplying the stomach of egret

\begin{tabular}{|l|l|l|}
\hline \multicolumn{1}{|c|}{ Artery } & \multicolumn{1}{c|}{ Origin } & \multicolumn{1}{c|}{ Distribution } \\
\hline $\begin{array}{l}\text { 1-Dorsal proven- } \\
\text { tricular artery }\end{array}$ & Celiac artery & $\begin{array}{l}\text {-Dorsal aspect of the proven- } \\
\text { triculus. } \\
\text {-Isthmus gastric. } \\
\text {-Thoracic esophagus. }\end{array}$ \\
\hline $\begin{array}{l}\text { 2-Ventral proven- } \\
\text { tricular artery }\end{array}$ & $\begin{array}{l}\text { Left branch of the } \\
\text { celiac artery }\end{array}$ & $\begin{array}{l}\text {-Ventral aspect of the proven- } \\
\text { triculus. } \\
\text {-Thoracic esophagus. }\end{array}$ \\
\hline $\begin{array}{l}\text { 3-Ventral gastric } \\
\text { artery }\end{array}$ & $\begin{array}{l}\text { Left branch of the } \\
\text { celiac artery }\end{array}$ & $\begin{array}{l}\text {-Ventral aspect of the proven- } \\
\text { triculus. } \\
\text {-Ventral aspect of the ventric- } \\
\text { ulus. } \\
\text { - Isthmus gastric. }\end{array}$ \\
\hline $\begin{array}{l}\text { 4- Left gastric ar- } \\
\text { tery }\end{array}$ & $\begin{array}{l}\text { Continuation of the } \\
\text { left branch of the } \\
\text { celiac artery }\end{array}$ & $\begin{array}{l}- \text { Ventral aspect of the ven- } \\
\text { triculus } \\
\text {-Ventral aspect of the proven- } \\
\text { triculus. }\end{array}$ \\
\hline $\begin{array}{l}\text { 5- Right gastric } \\
\text { artery }\end{array}$ & $\begin{array}{l}\text { Right branch of } \\
\text { the celiac artery }\end{array}$ & $\begin{array}{l}\text {-Dorsal aspect of the ventricu- } \\
\text { lus (craniodorsal tenuis, cau- } \\
\text { doventral tenuis muscles and } \\
\text { centrum tendineum) }\end{array}$ \\
\hline $\begin{array}{l}\text { 6-Gastroduodenal } \\
\text { artery }\end{array}$ & $\begin{array}{l}\text { Right branch of the } \\
\text { celiac artery }\end{array}$ & $\begin{array}{l}\text { - Pyloric region and the initial } \\
\text { portion of the duodenum de- } \\
\text { scendens. }\end{array}$ \\
\hline
\end{tabular}




\section{Legend for figures (1-3)}

I-V: Costae (numerical), a- Kidney, b- Heart, c- Liver, d-Esophagus, e- Proventriculus, fGizzard, f1- Pars pylorica ( $3^{\text {rd }}$ stomach), g- Descending duodenum, h- Ascending duodenum, i- Pancreas, j- Jejunum, k- Ileum., l- Coloaca, m- Gall bladder, n- Spleen, o- Left cecum, p- Colorectum, 1- Aorta descenedens, 2- A.celiaca, 3- A.mesenterica cranialis, 4-A. esophagealis, 4a- Rr. of A. esophagealis, 5-A. proventricularis dorsalis, 5a- $\mathrm{Rr}$. esophageales of 5, 5b- Rr. collaterales of 5, 6- A. esophagealis of 5, 7- Aa. Lienales, 8A. hepatica, 9- Ramus dexter arteriae celicae, 10- Ramus sinster arteriae celicae, 11- A. proventrcularis ventralis, 11a- Rr. esophageales of 11, 12- A. gastrica ventralis, 13- A. gastrica sinistra, 14- Rr. collaterales of 13, 15-R. of Pars pylorica, 16- Aa. ileocecales, 17- Rr. succi, 18- A. gastrodudenalis, 19- A .jejunalis of 10, 20- A .jejunalis of 22, 21- A. gastrica dextra, 22- A. pancreaticoduodenalis, 23- Rr. Pancreatici of 22, 24- Rr. duodenales of 22 .

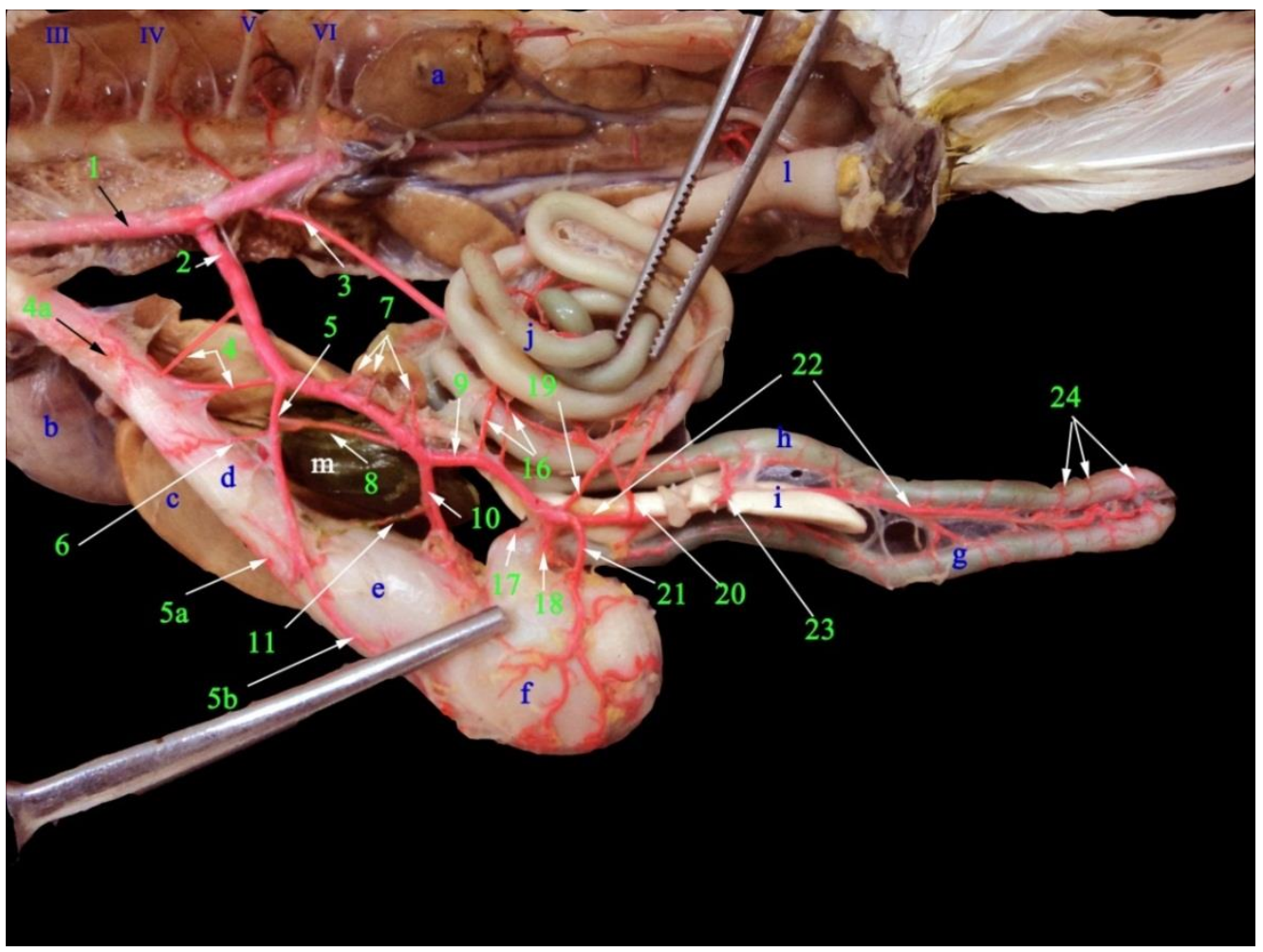

Fig (1): A photograph showing branches of the celiac artery in Cattle egret, right lateral view. 


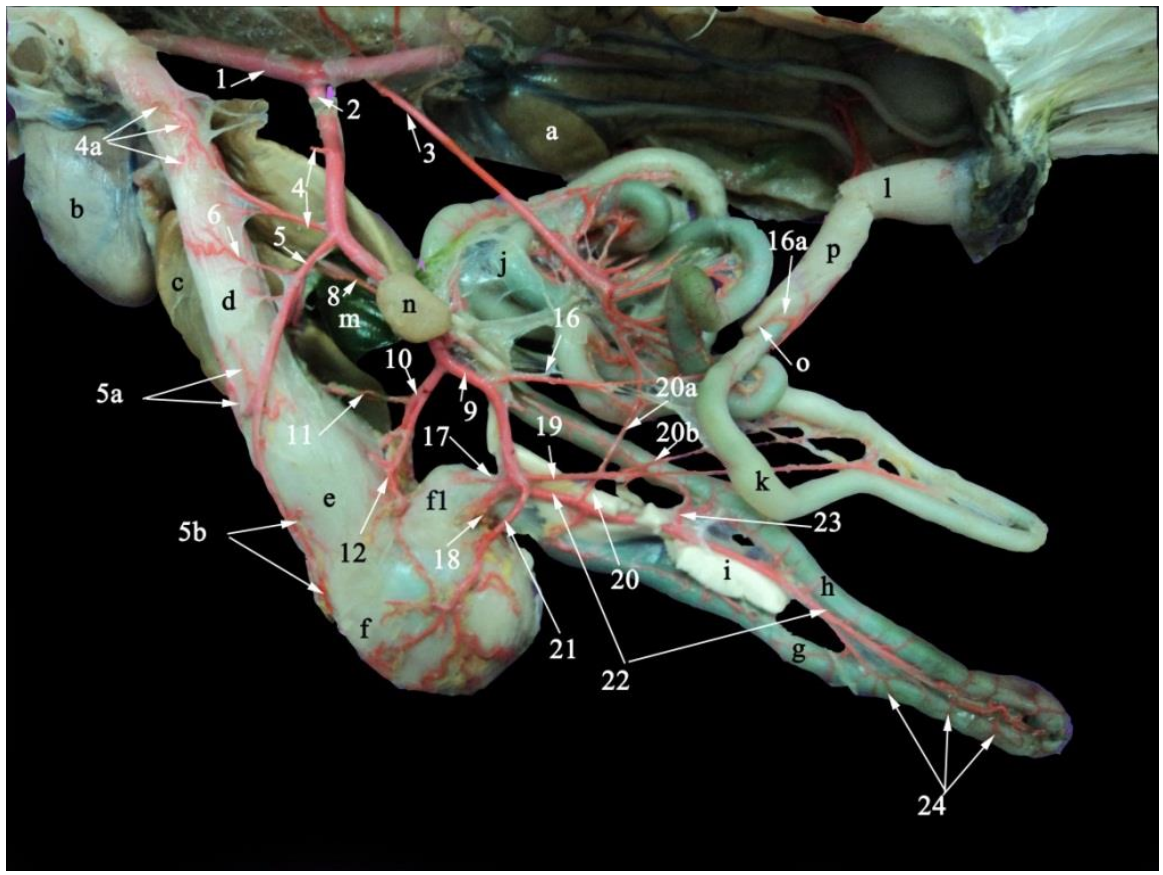

Fig (2): A photograph showing branches of the celiac artery in Cattle egret, right lateral view.

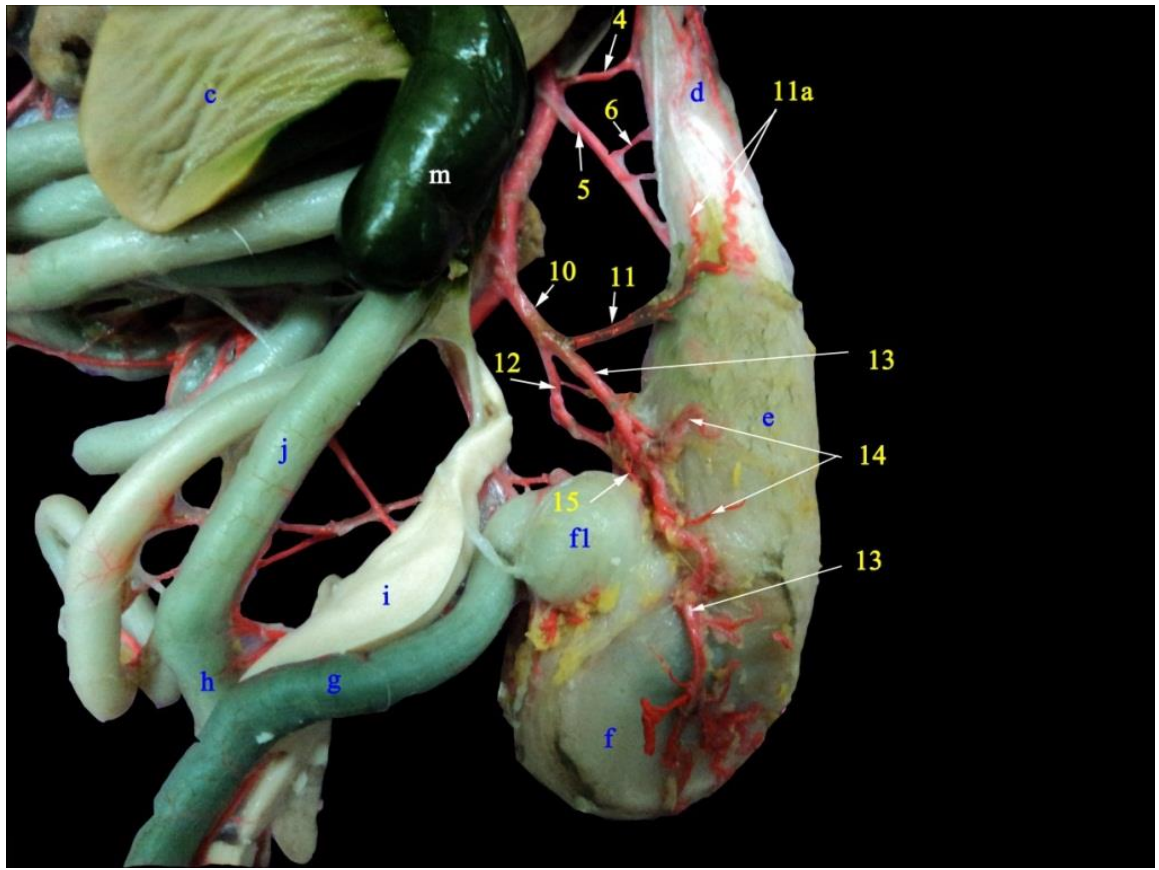

Fig (3): A photograph showing branches of the left ramus of the celiac artery in Cattle egret left lateral view. 


\section{Animals of this issue}

\section{Cattle Egret (Bubulcus ibis)}

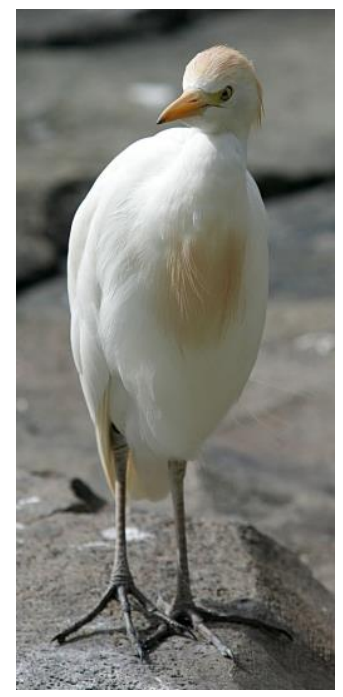

Kingdom: Animalia \& Phylum: Chordata \& Class: Aves \& Subclass: Neomithes \& Infraclass: Neognathae \& Superorder: Neoaves \& Order: Pelecaniformes \& Family: Ardeidae \& Genus: Ardea \& Species: $A$. cinerea

The Cattle Egret (Bubulcus ibis) is a cosmopolitan species of heron (family Ardeidae) found in the tropics, subtropics and warm temperate zones. It is the only member of the monotypic genus Bubulcus, although some authorities regard its two subspecies as full species, the Western Cattle Egret and the Eastern Cattle Egret. Despite the similarities in plumage to the egrets of the genus Egretta, it is more closely related to the herons of Ardea. Originally native to parts of Asia, Africa and Europe, it has undergone a rapid expansion in its distribution and successfully colonised much of the rest of the world.

The positioning of the egret's eyes allows for binocular vision during feeding, and physiological studies suggest that the species may be capable of crepuscular or nocturnal activity. Adapted to foraging on land, they have lost the ability possessed by their wetland relatives to accurately correct for light refraction by water.

This species gives a quiet, throaty rick-rack call at the breeding colony, but is otherwise largely silent.

Source: Wikipedia, the free encyclopaedia 